Open Journal of Gastroenterology and Hepatology
(ISSN:2637-4986)

\title{
Colon Irrigation Bowel Preparation Supports Multiple Clinical Benefits in Over 8,000 Patients
}

\author{
Chris GodelI ${ }^{1}$, Robert Frachtman ${ }^{1}$, Christopher Peake ${ }^{1,2}$, Richard M. Sperling ${ }^{1}$, Benjamin D. \\ Havemann ${ }^{1}$, John J. Ziebert ${ }^{1^{*}}$
}

${ }^{1}$ Austin Gastroenterology, Austin, TX, USA. ${ }^{2} \mathrm{HCA}$ Healthcare, Austin, TX, USA.

\begin{abstract}
This retrospective clinical study evaluates an FDA-cleared high-volume colon irrigation bowel prep (BP) for colonoscopy, performed under standard operating procedures with Austin Gastroenterology (AG, Austin, TX). Patient related outcomes in 8,364 procedures, prescribed by 33 physicians in 4.5 years, demonstrated no serious adverse events and excellent satisfaction rates. The high level of adequacy using this BP far exceeds national benchmarking thresholds for adequate colon preparations. Adequacy rates remain high even when considering poor BP risk factors and patient noncompliance with ancillary pre-preparation regimens. Our analysis demonstrates that this colon irrigation BP has excellent Boston bowel preparation scores (BBPS), associated with high-level adenoma detection rates (ADR) and sessile serrated polyp (SSP) detection rates. ADR and SSP are inversely related to the patient's post-colonoscopy interval colorectal cancer $(\mathrm{CRC})$ risk, and are similarly related to an inadequate BP. Both modeling data and performance characteristics strongly suggest that this colon irrigation BP is highly safe, effective, and will reduce the costs and risks related to inadequate BP. This, accordingly, leads to significantly improved quality outcomes, savings to the healthcare systems, and a reduction of the patient's burden.
\end{abstract} ${ }^{*}$ Correspondence to Author: John J. Ziebert

Austin Gastroenterology, Austin, TX, USA.

Keywords: colonoscopy; colon preparation; colonoscopy quality; How to cite this article:

Chris Godell, Robert Frachtman, Christopher Peake, Richard M. Sperling, Benjamin D. Havemann, John J. Ziebert. Colon Irrigation Bowel Preparation supports multiple clinical benefits in over 8,000 patients. Open Journal of Gastroenterology and Hepatology, 2021; $4: 48$ ADR; SSP; CRC

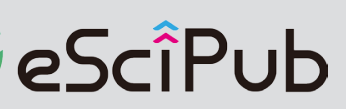

eSciPub LLC, Houston, TX USA. Website: https://escipub.com/ 


\section{Introduction}

Gastroenterologists use colonoscopies as the tool of choice for colorectal cancer (CRC) prevention and screening, as it allows for both visualization and polyp removal in the lower gastrointestinal tract ${ }^{[1,2]}$. CRC is the third most common cancer in the United States ${ }^{[3]}$. An updated survey from the American Cancer Society (ACS) projects that in 2020, almost 150,000 new cases will be diagnosed, and over 53,000 will die from the disease ${ }^{[4]}$. Overall, both CRC incidence and mortality have significantly decreased over the past two decades due to the expansion of colonoscopy screening coverage by Medicare and other commercial insurance carriers and health maintenance groups (HMOs) [5]. According to the Centers for Disease Control and Prevention (CDC), almost $70 \%$ of adults aged 50-75 undergo colonoscopies at the recommended frequency. However, up to $20 \%$ of colonoscopies are reported to have inadequate bowel preparation (BP), resulting in lower detection rates, lengthier procedures, early repeat procedures, and increased costs ${ }^{[6-}$ 12]. Incremental colonoscopy related health system cost estimates, as a result of an inadequate BP, have been reported to be $12 \%$ and $22 \%$ for university and public hospitals, respectively [13]. For these reasons, BP regiments have increasingly become standardized, with multiple publications of international guidelines and suggested quality scales for assessing adequacy [12,14-16]. The standardized and clinically validated Boston bowel preparation score (BBPS) scores the cleanliness of each of the three bowel segments (ascending, transverse, and descending) on a scale of $0-3$, during withdrawal and after washing [14]. The BBPS scores are highly correlated to adequate BP for colonoscopy [17], defined as a total score of over $6{ }^{[18]}$. More recent data have suggested that segmental scores of $<2$ correlate with missed high-risk adenomas ${ }^{[19]}$.

A key measure of colonoscopy quality is the adenoma detection rate (ADR), the percentage of patients aged $\geq 50$ years with an adenoma detected and removed during their first-time screening colonoscopy ${ }^{[18]}$. It is widely accepted that the ADR is a significant parameter for colonoscopy quality and is inversely correlated to interval cancer risk ${ }^{[20]}$. However, it appears that adenomas account for only $70 \%$ of CRCs, and approximately 30\% arise through the serrated pathway, which is also a disproportionate contributor to interval CRC [21]. Notably, the pathway for sessile serrated polyps (SSP), found in approximately $5-7 \%$ of screening colonoscopies, is often detected in the proximal colon, thus hindering detection. Missed lesions, or incomplete removal of precancerous polyps, often due to inadequate BP, are estimated to account for up to $80 \%$ of interval cancers [22]. Thus, high-quality BP is crucial for both the identification and removal of colorectal lesions.

The current standard of care (SOC) BP protocol is a split dose administration of an oral purgative. Recognizably, this often causes severe

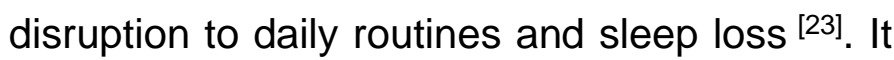
is also associated with low patient satisfaction [24], which inevitably reduces compliance with screening guidelines and surveillance recommendations. Noncompliance with preprep instructions accounts for over $20 \%$ of inadequate BP cases [10,25-28]. Oral purgative BPs are generally considered safe and welltolerated with common side-effects that include nausea, vomiting, and electrolyte disturbances [12]. Although the split oral dose is the current SOC, results demonstrate that up to $20 \%$ of outpatient and up to $60 \%$ of inpatient colonoscopies [12] can result in incomplete or 
low-quality colonoscopies due to inadequate $\mathrm{BP}$ [29]. The probability of inadequate $\mathrm{BP}$ is correlated with patient-specific factors, including age, male gender, medications, and several comorbidities ${ }^{[30-33]}$. These comorbidities include chronic constipation, diabetes, gastrointestinal surgery, cirrhosis, obesity, stroke, and irritable bowel disease (IBD) [12,25,33,34]. Following inadequate $\mathrm{BP}$, patients often require a repeat procedure, leading to an increased burden on the healthcare system and the patients ${ }^{[34,35]}$.

A novel method has been developed to decrease inadequate $\mathrm{BP}$ rates and increase patient satisfaction and compliance. This FDAcleared open-system is based on purging the colon by low pressure (gravity directed) highvolume irrigation on the day of the colonoscopy. The system, operating in dedicated centers under stringent standard operating procedures (SOPs) and located in proximation to endoscopy centers, is well-tolerated and highly effective ${ }^{[36-}$ 39]. This retrospective review reports real-world evidence (RWE) of clinical outcomes derived from this high-volume colon irrigation BP by analyzing 8,364 procedures prescribed to 7,988 patients in 4.5 years.

\section{Methods}

Collection and statistical analysis of demographic and clinical information -

This retrospective database analysis is based on de-identified clinical and demographic data of patients who received high-volume colon irrigation BP. Data was collected at the Austin Gastro-Hygieacare center (AG-Hygieacare, Austin, TX) between August 2015 and December 2019. During this time, 8,364 procedures, performed on 7,988 patients, were prescribed by 33 physicians. The demographic and selfreported clinical data were collected via patient questionnaires. The center's staff documented adverse events (nausea, vomiting, dizziness, and abdominal cramping) occurring during and immediately after the high-volume colon irrigation BP. The Boston bowel preparation score (BBPS), a 10-point scale (0-9) assessing $\mathrm{BP}$, was completed by the endoscopist after all cleansing protocols and was used to assess bowel cleanliness levels. BBPS data were recorded for 7,624 patients between November 2015 and December 2019. The analysis is presented as an average score per year, including a statistical analysis to assess significant changes between the years. The analysis of the distribution of procedures' BBPS scores is presented as a percentage of the total cohort (Figure 1). For a subset of these patients $(n=2,652)$, BBPS was also recorded as individual scores per segment (0-3), ascending, transverse, and descending, segment scores. An analysis of these segments' scores is also presented by year. Statistical analysis to assess significant improvement from the previous year was done using one-way ANOVA with a Tukey HSD post-hoc test $\left({ }^{*} p<0.05,{ }^{* *} p<0.005\right)$. Since this is a retrospective descriptive review of a standard FDA-cleared and unchanged approved procedure, de-identified and with patient consent, no IRB was required.

Analysis of high-volume colon irrigation $B P$ sensitivity to predictors for poor $B P$

To check for a correlation between predictors for inadequate BP factors (male gender, advanced age, and comorbidities) and poor BP, we analyzed all database entries with recorded clinical outcomes (adequacy reported) and documented age and/or gender. We found 6,316 procedures with reported age and adequacy (Figure 3). Patients were divided into eight age groups (under 35, 36-45, 46-55, 56-65, 66-75, 76-85, and over 86). The statistical difference between BP adequacy across the different age OJGH: https://escipub.com/open-journal-of-gastroenterology-and-hepatology/ 
groups was compared using a nonparametric Kruskal-Wallis test ( $p<0.05, R$ software). Patient self-reported comorbidities were recorded over 13 months, September 2016-September 2017. The comorbidities include chronic constipation, diabetes, irritable bowel disease (IBD), irritable bowel syndrome (IBS), carcinoma of the rectum, cirrhosis, colon surgery, abdominal surgery, rectal surgery, intestinal obstruction, stricture, abdominal hernia, heart conditions, and intestinal perforation. This analysis is presented for 2,240 consecutive indexed procedures. The specific comorbidities are reported as a percentage of adequate procedures from all documented procedures where a particular comorbidity was recorded.

Data collection for the sensitivity of the highvolume colon irrigation $B P$ to different pre-prep regimes-

To allow for improved clinical outcomes, physicians prescribed pre-colonoscopy BP instructions to patients, regardless of the chosen method. These include a clear liquid or a low residue diet with laxatives, such as bisacodyl and Magnesium hydroxide, given in various combinations and doses. The effectiveness of the high-volume colon irrigation $\mathrm{BP}$, relative to other pre-prep regimes, was determined in those cases where these specifics were reported. A correlation of pre-prep regimes to BBPS scores, overall and for each colon segment, was tested for a subset of 297 patients for which this information was available. Compliance with the physician's pre-prep instructions was defined as four tablets of $5 \mathrm{mg}$ bisacodyl (2 tablets twice a day for one day) and 10 tbsp of Magnesium hydroxide (2 tbsp for 5 nights). The total BBPS score and BBPS per intestinal segment were compared between the compliant and noncompliant groups using a two-tailed T-test ( $p<0.05, R$ software).

OJGH: https://escipub.com/open-journal-of-gastroenterology-and-hepatology/
Adenoma and sessile serrated polyps detection rates

The adenoma detection rates (ADR) and detection rates of sessile serrated polyps (SSP) are routinely collected by Austin Gastroenterology (Austin, TX) as part of the endoscopy center routine colonoscopy for quality metrics. Patients who chose the highvolume colon irrigation BP and met the analysis criteria were included in the analysis (October 1 , 2018 to June 31,2019$)$. The criteria were as follows: patients must be asymptomatic; age > 45 and African American or $>50$ (all other ethnicities); and must be undergoing their initial screening colonoscopy. The search yielded 112 eligible patients examined by 18 physicians. This analysis was performed retrospectively on a de-identified dataset.

Patient satisfaction analysis and willingness to repeat the colonic irrigation procedure-

To estimate patient satisfaction with the highvolume colonic irrigation BP procedure, all patients were asked to fill out a standard postprocedure satisfaction survey. The survey included four questions relating to their experience with the BP. Answers were ranked on a 4-point scale from definitely agree to definitely disagree. Two additional questions evaluated the patients' willingness to choose this BP for their next procedure, and the patients' willingness to recommend this BP to a friend. Patient responses were analyzed by counting responses in each bracket, and results are presented as a percentage of the total maximum response. Additionally, we report on patients that have chosen the high-volume colon irrigation BP more than once over the reported time period, August 2015 to December 2019. 


\section{Results}

Clinical outcome, BP adequacy, and demographic information

Between August 2015 and December 2019, the high-volume colon irrigation BP for colonoscopy was performed 8,364 times in 7,988 patients, as prescribed by 33 gastroenterologists from Austin Gastroenterology (AG, Austin, TX). Patients' age ranged from 18-96 (average $=62 \pm 11$ ), 61\% of the procedures with assigned gender were performed on females and $39 \%$ on males. Out of the 8,364 procedures performed during this time, 7,624 had reported outcomes. The BBPS score was $8.20 \pm 1.38$ for all reported procedures, and $80 \%$ of all procedures had a total BBPS of 8 or 9 (Table 1, Figure 1). The BP adequacy scores, defined herein as BBPS $\geq 6$, improved throughout the years. The BBPS significantly increased between $2015(n=149)$ and $2016(n=1,909)$ and between 2016 and $2017(n=2,181)$ (ANOVA with a Tukey HSD post-hoc test, $p<0.005$, Figure 2). Between January 2017 and December 2019, over $96 \%$ of the patients, including patients with underlying diseases, were reported to have BBPS $\geq 6$, with an average of $8.28 \pm 1.36$ $(\mathrm{n}=5,566)$.

Statistical analysis of the BBPS per segment (ascending, transverse, and descending, $\mathrm{n}=2,652$ ) revealed significant progressive improvements in segmental BBPS scores throughout the years (Table 2), probably due to increased staff experience. For the ascending colon, a statistically significant improvement was detected between 2015 and 2016 (ANOVA with a Tukey HSD post-hoc test, $\mathrm{p}<0.005$ ) as well as between 2017 and $2018(\mathrm{p}<0.05)$, reaching BBPS of $2.70 \pm 0.53$ and $96 \%$ patients with segmental $B B P S \geq 2$. The transverse colon segmental BBPS also showed statistically significant increased cleanliness between the years, it averaged $2.87 \pm 0.36$ in $2018(n=278)$, and $99 \%$ of the patients recorded segmental $B B P S \geq 2$. The descending colon BBPS score constantly improved, however, not significantly. In 2018, the descending colon BBPS score was $2.89 \pm 0.35$. Overall, our results show that since 2017 , reported outcomes reveal that $96 \%$ of the ascending colon, $98 \%-99 \%$ of the transverse colon, and $98-99 \%$ of the descending colon have a BBPS $\geq 2$ (Table 2).

No serious adverse events (SAE) were recorded in the 8,364 procedures. Minor adverse events (AE) were reported in $13 \%$ of the procedures $(n=1,098)$. Nausea, vomiting, dizziness, and abdominal cramping were reported for $8 \%$ $(n=662), 1.3 \%(n=107), 3 \%(n=266)$, and $6 \%$ $(n=492)$ of the procedures, respectively. Of the 1,031 procedures for which both $A E$ and clinical outcomes were recorded, 97.6\% $(n=1,007)$ reported an adequate outcome. Demographics and key results are presented in Table 1.

High-volume colon irrigation $B P$ sensitivity to predictors for poor BP

There are three main predictors for inadequate BP: male gender, age, and a variety of comorbidities ${ }^{[40]}$. Our database included 4,312 high-volume colon irrigation procedures with disclosed gender and reported clinical outcome. Of these, $61 \%(n=2,642)$ were performed on females and $39 \%(n=1,670)$ on males. BP adequacy for colonoscopy of these patients was $98 \%$, regardless of reported gender. An additional 3,129 procedures with reported clinical adequacy, but no assigned gender, had $96 \%$ adequacy. The database had 6,316 indexed procedures with detailed age and reported clinical outcomes. The age range was 18-96, with an average of $62 \pm 11$, and $43 \%$ were over 66 years of age. Patients ages 18 to 75 demonstrate over $97 \%$ adequacy $(n=5,726)$, while patients over $76(n=590)$ present 95\% 
adequacy (Figure 3). We then performed statis- groups (K-W test, $\mathrm{p}<0.05)$. For all age groups, tical analysis to determine whether there were the adequacy of the high colon irrigation BP was differences in the adequacy between age groups over $95 \%$.

and found no significant difference between the

Table 1 Key demographics and summary of key results. All patients underwent high-volume colon irrigation bowel preparation for colonoscopy as prescribed by physicians affiliated with Austin Gastroenterology (Austin, TX), between August 2015 and December 2019.

\begin{tabular}{|l|l|}
\hline Parameter & Summary of demographic data and key results \\
\hline Procedures performed in the center & 8,364 \\
\hline Number of patients & 7,998 \\
\hline Number of referring physicians & 33 \\
\hline Overall Boston bowel prep score (BBPS) & $8.20 \pm 1.38(\mathrm{n}=7,624)$ \\
\hline BBPS by segment & $\begin{array}{l}\text { Ascending }-2.5 \pm 0.65 \\
\text { Transverse }-2.74 \pm 0.52 \\
\text { Descending- } 2.81 \pm 0.46 \\
(\mathrm{n}=2,652)\end{array}$ \\
\hline Age of patients & $\begin{array}{l}\text { min }-18 ; \text { max }-96 ; \text { average- } 62 \pm 11 \\
(\mathrm{n}=6,316)\end{array}$ \\
\hline Gender of patients & $\begin{array}{l}\text { Male }-2,642(39 \%) \\
\text { Female }-1,670(61 \%) \\
(\mathrm{n}=4,321)\end{array}$ \\
\hline Serious adverse events & 0 \\
\hline Other adverse events & $\begin{array}{l}13 \% \quad(\mathrm{n}=1098) \text { reported some adverse events (nausea, } \\
\text { vomiting, dizziness and/or abdominal cramping) }\end{array}$ \\
\hline Patients that have had multiple procedures & 343 \\
\hline
\end{tabular}

Table 2 Boston bowel prep score (BBPS) per segment divided according to available data from 2015-2018. Asterisks indicate statistically significant improvements from the previous year $\left({ }^{*} p<0.05\right.$, $\left.{ }^{* *} \mathrm{p}<0.005\right)$.

\begin{tabular}{|l|c|c|c|c|c|}
\hline \multicolumn{2}{|l|}{ Colon segment } & $\mathbf{2 0 1 5} \mathbf{( n = 1 4 9 )}$ & $\mathbf{2 0 1 6} \mathbf{( n = 1 , 9 0 5 )}$ & $\mathbf{2 0 1 7}(\mathbf{n = 3 2 0})$ & $\mathbf{2 0 1 8}(\mathbf{n}=\mathbf{2 7 8})$ \\
\hline Ascending & score & $2.32 \pm 0.71$ & $2.49 \pm 0.66^{* *}$ & $2.56 \pm 0.58$ & $2.70 \pm 0.53^{*}$ \\
\cline { 2 - 6 } BBPS & $\geq 2$ & $88 \%$ & $93 \%$ & $96 \%$ & $96 \%$ \\
\hline \multirow{2}{*}{$\begin{array}{l}\text { Transverse } \\
\text { BBPS }\end{array}$} & $\mathbf{s c o r e}$ & $2.60 \pm 0.60$ & $2.74 \pm 0.52^{* *}$ & $2.82 \pm 0.43^{*}$ & $2.87 \pm 0.36$ \\
\cline { 2 - 6 } $\begin{array}{l}\text { Descending } \\
\text { BBPS }\end{array}$ & $\mathbf{2}$ & $95 \%$ & $97 \%$ & $98 \%$ & $99 \%$ \\
\cline { 2 - 6 } & $\mathbf{s c o r e}$ & $2.72 \pm 0.56$ & $2.80 \pm 0.46$ & $2.86 \pm 0.39$ & $2.89 \pm 0.35$ \\
\hline
\end{tabular}

Comorbidities, as self-reported by the patients, 27 physicians between September 2016 and were recorded for 2,233 consecutive procedures September 2017. Of these procedures, 2,075 performed on 2,190 patients and prescribed by had reported clinical outcomes with $97 \%$ 
adequacy for colonoscopy $(n=2,014)$. Comorbidities were reported in $24 \%$ of the performed procedures $(n=537$, prescribed by 26 physicians). The procedures' comorbidities and clinical outcomes are reported in Table 3 and include constipation, diabetes, IBS, IBD, other gastrointestinal conditions, renal disease, and cardiac conditions ( $n=2-195$ per comorbidity). BP adequacy was $>92 \%$ among all comorbidities listed, except one. Out of 7 patients with cirrhosis that underwent the highvolume colon irrigation BP during the reported period, 6 had an adequate BP, accounting for $86 \%$ adequacy.
Sensitivity to pre-prep regimes

To examine whether pre-BP affects adequacy, we checked for differences in BBPS in a subcohort of 281 patients for whom we had selfreporting on their pre-prep compliance. We compared patients that were compliant with physician's pre-prep instructions to patients who did not. Compliance was defined as $2 \times 5 \mathrm{mg}$ bisacodyl (2 tablets twice a day for one day) and 10 tbsp of Magnesium hydroxide (2 tbsp for 5 days). There were no statistical differences (twotailed $T$-test, $P<0.05)$ between the groups in overall BBPS and BBPS scores per colon segment (Table 4).

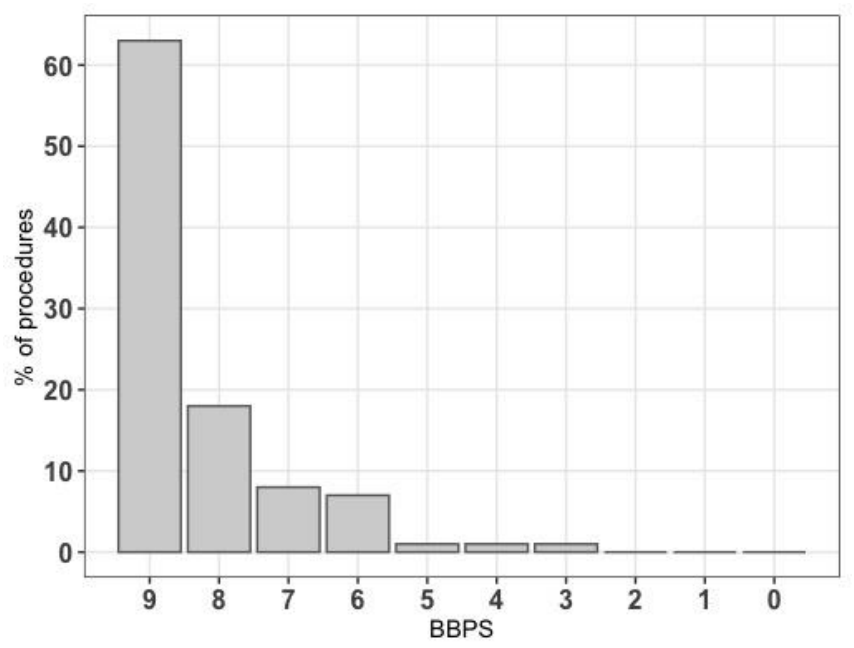

Figure 1 Percent of all procedures performed between 2015 and 2019 according to total Boston bowel prep score (BBPS) $(n=7,624)$.

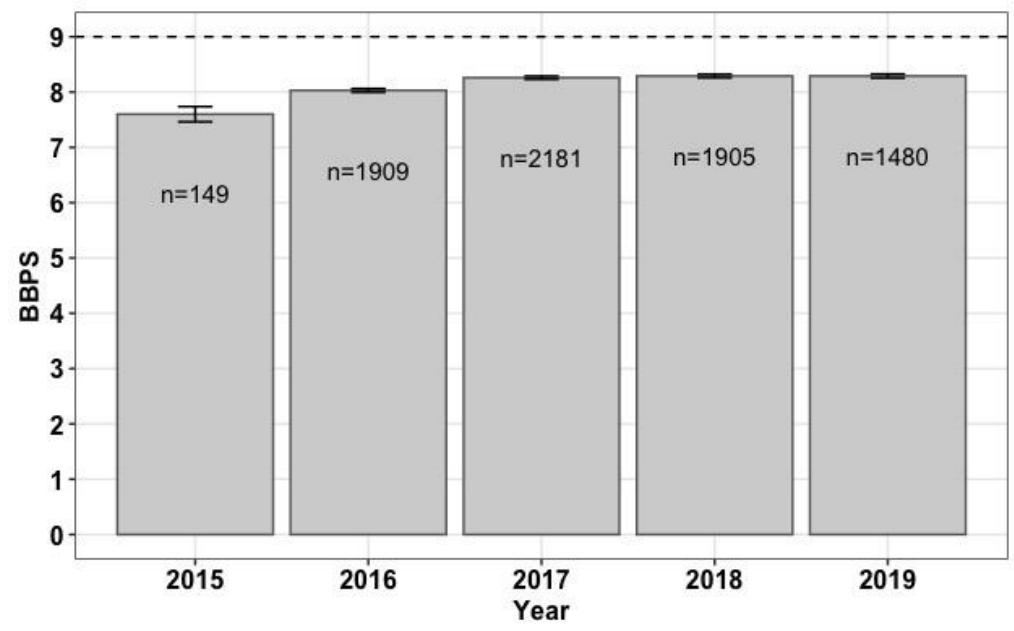

Figure 2 Annual Boston bowel prep score (BBPS) average for 2015-2019 $(n=7,624)$. Bars represent \pm SEM (standard error of the mean), the number of high-volume water colon irrigation procedures from each year is noted in the bars. Dashed line at BBPS=9 represents the maximum possible BBPS. Asterisks represent significant difference between annual average BBPS scores $\left({ }^{* \star *} p<0.005\right)$. 


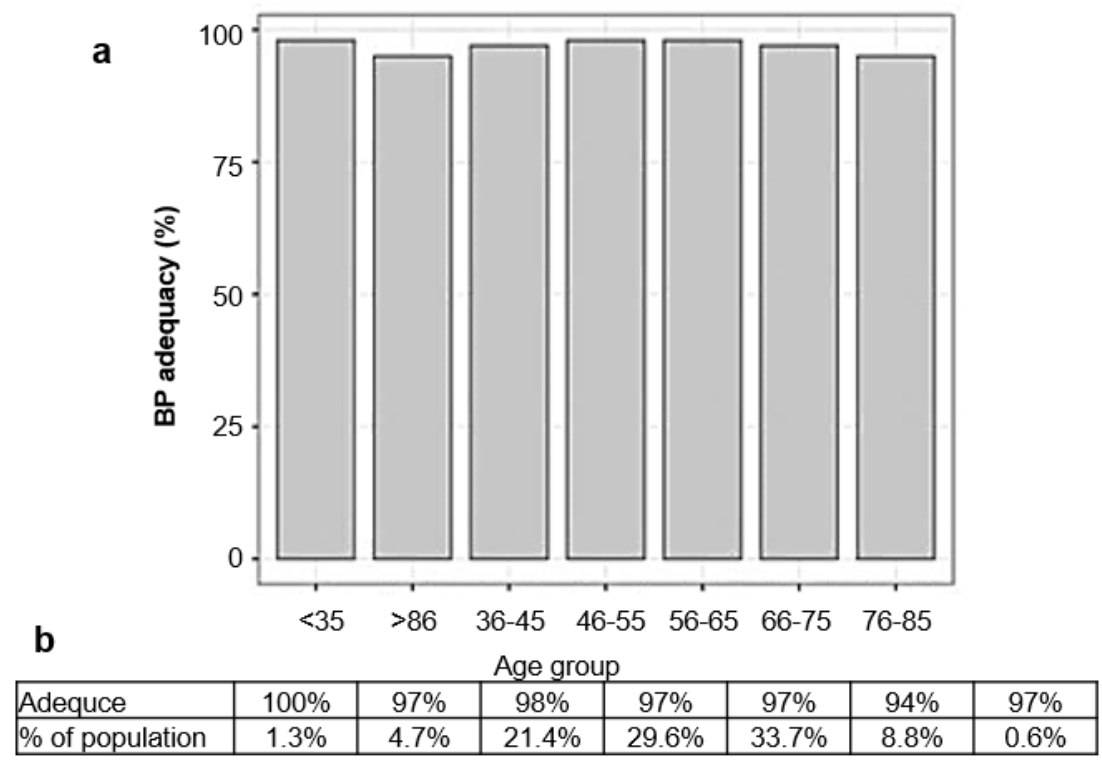

Figure 3 Bowel prep adequacy of high-volume water colon irrigation procedures performed between August 2015 and December 2019 divided by age group (for procedures with disclosed age). Adequacy is defined as Boston bowel prep score (BBPS) $\geqq 6, n=6316$. a. Represented as a bar graph of adequacy versus age group. b. Represented as a table with all number of patients and adequacy information.

Adenoma and sessile serrated polyps detection rates

A sub-population of 112 average-risk patients, $43 \%$ male, $57 \%$ female, were analyzed for ADR and SSP detection rates. All patients were scheduled for their first colonoscopy and chose the high-volume colon irrigation for $\mathrm{BP}$, as prescribed by 18 physicians. The physicians in this study prescribed 1-14 procedures, with an average of $6.2 \pm 4.7$ procedures per physician. All procedures were recorded at $99 \%$ adequacy for BP (111 of 112 patients), with an average BBPS of $8.3 \pm 1.3$. The ADR was $46 \%$ on average, $60 \%$ in males and $34 \%$ in females. The SSP detection rate after high-volume colon irrigation BP was $12.5 \%$ (Table 5).

\section{Patient satisfaction}

Following their colon irrigation $\mathrm{BP}$, patients were asked to assess their experience and willingness to repeat the procedure for their next colonoscopy. In over 4,500 patients, 99\% reported positive responses to all survey questions (Table 6). The average percentage for "definitely agree" for the four post-BP questions was $92.3 \%$. In addition, 3,494 patients responded to the question "For my next colonoscopy, I would choose this BP again". Of these, $97.3 \%$ marked that they "definitely agree" $(n=2,888)$ and "agree" $(n=512)$ to use the highvolume colon irrigation BP for their next colonoscopy. The patients were also asked to rank their willingness to recommend this $\mathrm{BP}$ to a friend from 0 to 10 , where 10 is the most willing and 0 is not at all willing to recommend ( $n=2,223$ responses). Ranking of 7-to-10 was chosen by $95 \%$ of the patients, $4 \%$ of the responders ranked the question as $4-$ to- 6 , and $1 \%$ marked 0-to-3.

Between August 2015 and December 2019, 343 patients who initially chose the high-volume colon irrigation BP selected this BP again for their follow-up colonoscopies (prescribed per medical needs). Approximately $18 \%$ of these patients had taken a traditional oral prep prior to past colonoscopies $(n=63)$, before choosing the 
high-volume colon irrigation BP. Within the four procedures. Overall, the 343 patients reported period, $90 \%$ of the 343 returning underwent 719 high-volume colon irrigation BPs, patients had done two of these procedures, and of which 343 were naive, and 376 were $9 \%$ had three colonoscopies. One patient had repeating procedures.

Table 3 Bowel prep adequacy after high-volume colon irrigation procedure in patients with various comorbidities. Adequacy is defined as Boston bowel prep score (BBPS) $\geqq 6$.

\begin{tabular}{|l|c|c|}
\hline Comorbidity & $\begin{array}{c}\text { Total number of performed } \\
\text { procedures }\end{array}$ & $\begin{array}{c}\text { Adequate procedures } \\
\text { (\% of performed procedures) }\end{array}$ \\
\hline Constipation & 195 & $185(95 \%)$ \\
\hline Diabetes & 100 & $97(97 \%)$ \\
\hline Irritable bowel syndrome (IBS) & 100 & $98(98 \%)$ \\
\hline Irritable bowel disease (IBD)/ & 62 & $60(97 \%)$ \\
\hline Crohn's disease / Ulcerative colitis & 62 & $57(97 \%)$ \\
\hline Other indications & 56 & $54(92 \%)$ \\
\hline Bladder or pelvic mesh & 50 & $48(96 \%)$ \\
\hline Severe hemorrhoids & 29 & $29(100 \%)$ \\
\hline Fissures or rectal fistula & 23 & $22(96 \%)$ \\
\hline Diarrhea & 14 & $14(100 \%)$ \\
\hline Intestinal obstruction/stricture & 13 & $13(100 \%)$ \\
\hline Stroke & 10 & $10(100 \%)$ \\
\hline Congestive heart failure & 10 & $10(100 \%)$ \\
\hline Clostridium difficile & 8 & $8(100 \%)$ \\
\hline Celiac disease & 7 & $6(86 \%)$ \\
\hline Cirrhosis & 5 & $5(100 \%)$ \\
\hline Renal insufficiency including dialysis & 5 & $5(100 \%)$ \\
\hline Carcinoma of the rectum & 2 & $2(100 \%)$ \\
\hline Intestinal perforation & 62 & \\
\hline
\end{tabular}

Table 4 Boston bowel prep score (BBPS) according to pre-prep regime as self-reported by consecutive patients, during July and August $2018(\mathrm{n}=281)$. The Austin Gastro instructions for colonoscopy patients were to take 2 tablespoons of Magnesium hydroxide for five days and $2 \times 25$ mg bisacodyl before their colonoscopy. Differences between the compliant and non-compliant groups were measured using a two-tailed T-test, $p<0.05$.

\begin{tabular}{|l|c|c|c|c|}
\hline & BBPS all & BBPS left & BBPS transverse & BBPS right \\
\hline Compliant $(\mathbf{n = 8 8})$ & $8.29 \pm 1.58$ & $2.82 \pm 0.53$ & $2.81 \pm 0.51$ & $2.82 \pm 0.53$ \\
\hline Not compliant $(\mathbf{n = 1 9 3 )}$ & $8.36 \pm 1.50$ & $2.87 \pm 0.43$ & $2.87 \pm 0.41$ & $2.71 \pm 0.54$ \\
\hline P (T-test) & 0.88 & 0.56 & 0.74 & 0.30 \\
\hline
\end{tabular}


Table 5 Adenomas detection rates (ADR) and detection rates of sessile serrated polyps (SSP) following traditional oral prep or high-volume colon irrigation bowel preparation procedure.

\begin{tabular}{|l|c|c|c|c|}
\hline & ADR average & ADR males & ADR females & $\begin{array}{c}\text { SSP detection } \\
\text { rate }\end{array}$ \\
\hline High-volume colon irrigation bowel prep & $46 \%$ & $60 \%$ & $34 \%$ & $12.5 \%$ \\
\hline Traditional oral prep & $25 \%$ & $30 \%$ & $20 \%$ & $5-7 \%$ \\
\hline
\end{tabular}

Table 6 Analysis of the patient's quality of service survey following the high-volume colon irrigation bowel prep procedure. Results are presented as the percentage of responses. The number of total responses to all four questions was $n=4,545$.

\begin{tabular}{|c|c|c|c|c|}
\hline \multirow[t]{2}{*}{ Patients satisfaction survey questions } & $\begin{array}{l}\text { Definitely } \\
\text { agree }\end{array}$ & Agree & Disagree & $\begin{array}{l}\text { Definitely } \\
\text { disagree }\end{array}$ \\
\hline & \multicolumn{2}{|c|}{ Definitely agree + Agree } & \multicolumn{2}{|c|}{ Definitely disagree + disagre $\epsilon$} \\
\hline \multirow[t]{2}{*}{ Check-in was welcoming and efficient } & $90 \%$ & $9 \%$ & $0 \%$ & $1 \%$ \\
\hline & \multicolumn{2}{|c|}{$99 \%$} & \multicolumn{2}{|c|}{$1 \%$} \\
\hline \multirow{2}{*}{$\begin{array}{l}\text { Explanation received from my tech about } \\
\text { what to expect was clear and to the point }\end{array}$} & $92 \%$ & $7 \%$ & $0 \%$ & $1 \%$ \\
\hline & \multicolumn{2}{|c|}{$99 \%$} & \multicolumn{2}{|c|}{$1 \%$} \\
\hline \multirow{2}{*}{$\begin{array}{l}\text { Techs were available as needed; } \\
\text { adequate privacy was kept }\end{array}$} & $94 \%$ & $5 \%$ & $0 \%$ & $1 \%$ \\
\hline & \multicolumn{2}{|c|}{$99 \%$} & \multicolumn{2}{|c|}{$1 \%$} \\
\hline \multirow{2}{*}{$\begin{array}{l}\text { Prep room and system were clean to my } \\
\text { satisfaction }\end{array}$} & $94 \%$ & $5 \%$ & $0 \%$ & $1 \%$ \\
\hline & \multicolumn{2}{|c|}{$99 \%$} & \multicolumn{2}{|c|}{$1 \%$} \\
\hline
\end{tabular}

\section{Discussion}

In this retrospective clinical study performed on Austin Gastroenterology patients (AG, Austin, $\mathrm{TX})$, we showed that a high-volume colon irrigation BP for colonoscopy is safe and effective. We recorded excellent patientreported satisfaction rates and no serious adverse events in 8,364 procedures performed on 7,998 patients. Minor AE were reported in $13 \%$ of the performed procedures. This number is significantly lower than those reported for high volume polyethylene glycol (PEG) oral prep (adverse events in $90 \%$ of patients), low volume PEG plus ascorbate (80\%), low volume PEG plus bisacodyl tablet (66\%) [41], and sodium phosphate (75\%) ${ }^{[42]}$. The high level of BP adequacy (overall BBPS $\geq 6,96 \%$ ) following high- volume colon irrigation BP far exceeds national benchmarking thresholds for quality [15,43]. Adequacy rates remain high even when considering poor BP risk factors, including male gender, advanced age, and underlying health conditions (Figure 3, Table 2). We conclude that the high-volume colon irrigation $\mathrm{BP}$ is superior to traditional oral purgative $\mathrm{BP}$ that have much lower adequacy rates, reported at $\sim 75 \%$ for high volume PEG [44] and $\sim 70 \%$ for sodium phosphate ${ }^{[45]}$. Our results also show that the high-volume colon irrigation $\mathrm{BP}$ is agnostic to the patient's age, gender, and comorbidities.

An additional important factor that does not affect the high-volume colonic irrigation efficiency is the ancillary pre-prep regime (Table 4). Before performing the BP, patients are often 
prescribed laxatives or stool softeners for a better colon cleansing. Although optimal BP requires patients to adhere to written instructions, patients often do not fully follow these instructions ${ }^{[46]}$. There is a significant association between compliance with pre-BP instructions and level of education, health literacy, functional status, income, and medication burden. Suboptimal colonic preparation is a significant problem, accounting for a reduced yield of screening colonoscopies and increased healthcare costs because of longer procedure times and aborted procedures. Since the highvolume colon irrigation BP is agnostic to preprep regiments (Table 4), we predict that it will reduce the costs and risks related to inadequate $\mathrm{BP}$ and ease patient burden.

The ADR is inversely related to the patient's post-colonoscopy CRC risk. SSP are particularly sensitive to inadequate BP due to their subtle morphology and flat appearance, making them difficult to visualize [21]. Improved methods and techniques to increase ADR and SSP detection rates will improve patient care and outcomes $[47,48]$. The FDA-cleared high-volume colon irrigation BP has excellent BBPS, ADR, and SSP detection rates (Table 5), exceeding the national benchmarks [49]. Thus, using the high-volume colon irrigation $\mathrm{BP}$ as an $\mathrm{SOC}$ is expected to improve patient care by increasing the detection of neoplastic polyps and reducing the risk for interval CRC.

Our RWE presented here reports on the safety and efficacy of 8,364 high-volume colon irrigation BP. Providing a BP that patients accept and reducing their burden can increase the likelihood that these patients will return for scheduled recommended subsequent colonoscopies [47]. In our data, the patients' responses to the satisfaction survey questions revealed that $99 \%$ of 4,545 patients responded positively to the questions, and $97 \%$ said that they would choose this BP for their next colonoscopy. Moreover, while the technology has been available to patients for less than five years, 343 Austin Gastroenterology patients chose this BP more than once (and up to four times, for a medically indicated follow-up colonoscopy) despite the out-of-pocket expenses. The out-of-pocket expense by patients was up to $\$ 245$ per BP. A Monte Carlo simulation previously predicted lifetime savings to the healthcare system of $\$ 150 \mathrm{M}$ for a cohort of 100,000 average-risk patients over 50 when using the high-volume colon irrigation $\mathrm{BP}$, compared to a traditional oral $\mathrm{BP}{ }^{[39]}$. The model predicted that the high-volume colon irrigation $\mathrm{BP}$ is economically preferred when costs are kept under $\$ 975$, proven safe, and adopted by a large cohort of physicians and patients. Another variable to which the model showed sensitivity was the willingness to pay repeatedly for the prep. The patient's willingness to repeat is demonstrated by the patients' post-procedure questionnaires responses and the 343 patients who already chose this BP method more than once. The predicted high BP tolerance is also expected to reduce the number of canceled colonoscopies [36]. These results have clear direct and indirect cost effects. Our RWE corroborates the Monte Carlo model assumptions and strengthens its prediction that the high-volume BP can lead to significant savings to the healthcare system and that highvolume colon irrigation $\mathrm{BP}$ is a dominant $\mathrm{BP}$ strategy.

\section{Acknowledgments}

We are extremely thankful to David A. Johnson, MD MACG FASGE MACP, for providing his comments and insights on our manuscript. All the data for this retrospective study were provided by Dawn Burleson, RN MBA CRA, and 
Orly Levitan, PhD, from Hygieacare Inc. (Norfolk, VA, USA). There was no external funding for this study.

\section{References}

[1] Chen C, Stock C, Hoffmeister M, Brenner H. Public health impact of colonoscopy use on colorectal cancer mortality in Germany and the United States. Gastrointest Endosc. 2018;87 (1):213-221.e2. doi:10.1016/j.gie.2017.04.005

[2] Zauber AG, Winawer SJ, O'Brien MJ, et al. Colonoscopic polypectomy and long-term prevention of colorectal-cancer deaths. $N$ Engl J Med. 2012;366(8):687-696.

doi:10.1056/NEJMoa1100370

[3] Bray C, Bell LN, Liang H, Collins D, Yale SH. Colorectal cancer screening. WMJ Off Publ State Med Soc Wis. 2017;116(1):27-33.

[4] Siegel RL, Miller KD, Sauer AG, et al. Colorectal cancer statistics, 2020. CA Cancer J Clin. 2020;70(3):145-164. doi:10.3322/caac.21601

[5] Schenck AP, Peacock SC, Klabunde CN, Lapin $\mathrm{P}$, Coan JF, Brown ML. Trends in colorectal cancer test use in the medicare population, 1998-2005. Am J Prev Med. 2009;37(1):1-7. doi:10.1016/j.amepre.2009.03.009

[6] Sulz MC, Kröger A, Prakash M, Manser CN, Heinrich $\mathrm{H}$, Misselwitz B. Meta-analysis of the effect of bowel preparation on adenoma detection: early adenomas affected stronger than advanced 16 adenomas. PLOS ONE. 2016;11(6). doi:10.1371/journal.pone.0154149

[7] Martin D, Walayat S, Ahmed Z, et al. Impact of bowel preparation type on the quality of colonoscopy: a multicenter community-based study. J Community Hosp Intern Med Perspect. 2016;6(2):31074. doi:10.3402/jchimp.v6.31074

[8] Guo R, Wang Y-J, Liu M, et al. The effect of quality of segmental bowel preparation on adenoma detection rate. BMC Gastroenterol.
2019;19(1): 119. doi:10.1186/s12876-019-10198

[9] Hendry PO, Jenkins JT, Diament RH. The impact of poor bowel preparation on colonoscopy: a prospective single centre study of 10571 colonoscopies. Colorectal Dis. 2007;9(8):745-748.doi:10.1111/j.1463-1318.200 7.01220.x

[10] Lebwohl B, Kastrinos F, Glick M, Rosenbaum AJ, Wang T, Neugut Al. The impact of suboptimal bowel preparation on adenoma miss rates and the factors associated with early repeat colonoscopy. Gastrointest Endosc. 2011;73(6):1207-1214. doi:10.1016/j.gie. 2011. 01.051

[11] Chokshi RV, Hovis CE, Hollander T, Early DS, Wang JS. Prevalence of missed adenomas in patients with inadequate bowel preparation on screening colonoscopy. Gastrointest Endosc. 2012;75(6):1197-1203. doi:10.1016/j.gie.2012.01.005

[12] Johnson DA, Barkun AN, Cohen LB, et al. Optimizing adequacy of bowel cleansing for colonoscopy: recommendations from the US multi-society task force on colorectal cancer. Gastroenterology. 2014;147(4):903-924. doi:10. 1053/j.gastro.2014.07.002

[13] Rex DK, Imperiale TF, Latinovich DR, Bratcher LL. Impact of bowel preparation on efficiency and cost of colonoscopy. Am J Gastroenterol. 2002;97(7):1696-1700. doi:10.1111/j.1572-0241. 2002.05827.x

[14] Kastenberg D, Bertiger G, Brogadir S. Bowel preparation quality scales for colonoscopy. World J Gastroenterol. 2018;24(26):2833-2843. doi:10.3748/wjg.v24.i26.2833

[15] Rex DK, Schoenfeld PS, Cohen J, et al. Quality indicators for colonoscopy. Gastrointest Endosc. 2015;81(1):31-53.doi:10.1016/j.gie.2014.07.05 8 
[16] Hassan C, East J, Radaelli F, et al. Bowel preparation for colonoscopy: European Society of Gastrointestinal Endoscopy (ESGE) Guideline - Update 2019. Endoscopy. 2019;51(08):775794. doi:10.1055/a-0959-0505

[17] Calderwood AH, Schroy PC, Lieberman DA, Logan JR, Zurfluh M, Jacobson BC. Boston Bowel Preparation Scale scores provide a standardized definition of adequate for describing bowel cleanliness. Gastrointest Endosc. 2014;80(2): 269-276. doi:10.1016/j.gie. 2014.01.031

[18] Rex DK. Defining the Adenoma Detection Rate. NEJM J Watch. 2015;2015. doi:10.1056/ nejmjw.NA39315

[19] Kluge MA, Williams JL, Wu CK, et al. Inadequate Boston Bowel Preparation Scale scores predict the risk of missed neoplasia on the next colonoscopy. Gastrointest Endosc. 2018;87(3):7 44-751. doi:10.1016/j.gie.2017.06.012

[20] Kaminski MF, Regula J, Kraszewska E, et al. Quality indicators for colonoscopy and the risk of interval cancer. N Engl J Med. 2010;362 (19):1795-1803. doi:10.1056/NEJMoa0907667

[21] Clark BT, Laine L. High-quality Bowel Preparation is required for detection of sessile serrated polyps. Clin Gastroenterol Hepatol. 2016;14(8): 1155-1162. doi:10.1016/j.cgh.20 16.03.044

[22] Lee YM, Huh KC. Clinical and biological features of interval colorectal cancer. clin endosc. 2017;50(3):254-260. doi:10.5946/ce.2016.115

[23] Longcroft-Wheaton G, Bhandari P. Same day versus split dose bowel preparation for afternoon colonoscopy: impact on mucosal visibility and patient quality of life. Gut. 2011;60(Suppl 1):A42. doi:10.1136/gut.2011.239301.83

[24] Chan W-K, Goh K-L. Evaluation of patient satisfaction of an outpatient colonoscopy service in an Asian tertiary care hospital. Gastroenterol
Res Pract. 2012;2012:1-6. doi:10.1155/2 012/ 561893

[25] Serper M, Gawron AJ, Smith SG, et al. Patient Factors That affect quality of colonoscopy preparation. Clin Gastroenterol Hepatol. 2014; 12(3):451-457. doi:10.1016/j.cgh.2013.07.036

[26] Zhang Y-Y, Niu M, Wu Z-Y, Wang X-Y, Zhao Y$Y, G u J$. The incidence of and risk factors for inadequate bowel preparation in elderly patients: A prospective observational study. Saudi $J$ Gastroenterol Off J Saudi Gastroenterol Assoc. 2018;24(2):87-92. doi:10.4103/sjg.SJG_426_17

[27] Anklesaria AB, Ivanina EA, Chudy-Onwugaje $\mathrm{KO}$, et al. The effect of obesity on the quality of bowel preparation for colonoscopy: results from a large observational study. J Clin Gastroenterol. 2019;53(6):e214. doi:10.1097/MCG.000000000 0001045

[28] Nguyen DL, Wieland M. Risk factors predictive of poor quality preparation during average risk colonoscopy screening: the importance of health literacy. J Gastrointestin Liver Dis. 2010;19 (4):369-372.

[29] Audibert C, Perlaky A, Glass D. Global perspective on colonoscopy use for colorectal cancer screening: A multi-country survey of practicing colonoscopists. Contemp Clin Trials Commun. 2017;7:116-121. doi:10.1016/j.conctc. 2017.06.008

[30] Baker FA, Mari A, Nafrin S, et al. Predictors and colonoscopy outcomes of inadequate bowel cleansing: a 10-year experience in 28,725 patients. Ann Gastroenterol. 2019;32(5):457462. doi:10.20524/aog.2019.0400

[31] Fayad NF, Kahi CJ, Abd El-Jawad KH, et al. Association between body mass index and quality of split bowel preparation. Clin Gastroenterol Hepatol. 2013;11(11):1478-1485. doi:10.1016/ j.cgh.2013.05.037 
[32] Hassan C, Fuccio L, Bruno M, et al. A predictive model identifies patients most likely to have inadequate bowel preparation for colonoscopy. Clin Gastroenterol Hepatol. 2012;10(5):501-506. doi:10.1016/j.cgh.2011.12.037

[33] Gandhi K, Tofani C, Sokach C, Patel D, Kastenberg D, Daskalakis C. Patient characteristics associated with quality of colonoscopy preparation: a systematic review and meta-analysis. Clin Gastroenterol Hepatol. 2018;16(3):357-369.e10.

doi:10.1016/j.cgh.2017.08.016

[34] Shah SA, Zhou E, Parikh ND. Factors affecting outpatient bowel preparation for colonoscopy. Int J Gastrointest Interv. 2019;8(2):70-73. doi:10.1 8528/ijgii180039

[35] Butterly LF, Nadel MR, Anderson JC, et al. Impact of colonoscopy bowel preparation quality on follow-up interval recommendations for average-risk patients with normal screening colonoscopies: data from the new hampshire colonoscopy registry. J Clin Gastroenterol. 2020;54(4):356-364. doi:10.1097/MCG.00000 0 0000001115

[36] Gagneja HK, Parekh P, Burleson DB, Johnson D. Patient satisfaction and willingness to pay out of pocket for future hygieacare preps: 2403 . Off J Am Coll Gastroenterol ACG. 2016;111:S1236.

[37] Parekh PJ, Oldfield ECI, Johnson DA. Bowel preparation for colonoscopy: what is best and necessary for quality? Curr Opin Gastroenterol. 2019;35(1):51-57. doi:10.109 7/MOG.000000 00 00000494

[38] Sportes A, Delvaux M, Huppertz J, Hernandez C, Gay G. Randomized trial comparing high volume rectal water irrigation with standard 4 I split-dose PEG preparation before colonoscopy. $J$ Gastroenterol Dig Dis. 2016;1(1).

[39] Das A, Parekh PJ, Bekal P, et al. Bowel preparation for colonoscopy: a comparative cost
- effective analysis of traditional per os purgatory prep v ersus a novel method using high - volume colonic water irrigation. Gastroenterol Hepatol Int J. 2017;2(4). doi:10.23880/GHIJ-16000132

[40] Mahmood S, Farooqui SM, Madhoun MF. Predictors of inadequate bowel preparation for colonoscopy: a systematic review and metaanalysis. Eur J Gastroenterol Hepatol. 2018;30(8): 819-826. doi:10.1097/MEG. 0000 000000001175

[41] Johanson JF, Popp JW, Cohen LB, et al. A randomized, multicenter study comparing the safety and efficacy of sodium phosphate tablets with 2L polyethylene glycol solution plus bisacodyl tablets for colon cleansing. $A m \mathrm{~J}$ Gastroenterol. 2007;102(10):2238-2246. doi:10.1111/j.1572- 0241.2007.01363.x17

[42] Heher EC, Thier SO, Rennke H, Humphreys BD. Adverse renal and metabolic effects associated with oral sodium phosphate bowel preparation. Clin J Am Soc Nephrol CJASN. 2008;3(5):14941503. doi:10.2215/CJN.02040408

[43] Anderson JC, Butterly LF. Colonoscopy: Quality Indicators. Clin Trans/ Gastroenterol. 2015;6(2): e77. doi:10.1038/ctg.2015.5

[44] Spada C, Cesaro P, Bazzoli F, et al. Evaluation of Clensia®, a new low-volume PEG bowel preparation in colonoscopy: Multicentre randomized controlled trial versus 4L PEG. Dig Liver Dis. 2017;49(6):651-656. doi:10.1016/j.dld. 2017.01.167

[45] Lee J, McCallion K, Acheson AG, Irwin ST. A prospective randomised study comparing polyethylene glycol and sodium phosphate bowel cleansing solutions for colonoscopy. Ulster Med J. 1999;68(2):68-72.

[46] Kunnackal John G, Thuluvath AJ, Carrier H, Ahuja NK, Gupta E, Stein E. Poor health literacy and medication burden are significant predictors for inadequate bowel preparation in an urban 
tertiary care setting. J Clin Gastroenterol. 2019;53(9):e382. doi:10.1097/MCG.0000 0000 00001177

[47] Rex DK, Boland RC, Dominitz JA, et al. Colorectal cancer screening: recommendations for physicians and patients from the U.S. multisociety task force on colorectal cancer. Off J Am Coll Gastroenterol ACG. 2017;112(7):10161030. doi:10.1038/ajg.2017.174
[48] Kahi CJ. Screening Relevance of Sessile Serrated Polyps. Clin Endosc. 2019;52(3):235238. doi:10.5946/ce.2018.112

[49] Anderson JC, Butterly LF, Weiss JE, Robinson CM. Providing data for serrated polyp detection rate benchmarks: an analysis of the New Hampshire Colonoscopy Registry. Gastrointest Endosc. 2017;85(6):1188-1194. doi:10.1016/j. gie. 2017.01.02018 